Asian Journal of Information Technology 11 (2): 77-82, 2012

ISSN: $1682-3915$

(C) Medwell Journals, 2012

\title{
Educational Advisor System Implemented by Web-Based Fuzzy Expert Systems
}

\author{
Mahdi Hassani Goodarzi and Vahid Rafe \\ Department of Software Engineering, Islamic Azad University, \\ Malayer Branch, Malayer, Iran
}

\begin{abstract}
Using of the Internet technology and the field of Fuzzy Expert Systems has proposed new branches of sharing and distributing knowledge. However, there has been a general lack of investigation in the area of web-based Fuzzy Expert Systems (FES). In this study, the issues associated with the design, development and use of web-based FES from a standpoint of the benefits and challenges of developing and using them. The original theory and concepts in conventional FES were reviewed and a knowledge engineering framework for developing them was revisited. Student in an educational place need an educational advisor for solve problems. Some of educational circulars order changing because advisor must update information away. The student's request is Linguistic and Crisp Expert System cannot solve problems completely. In my approach we build Web-Based Fuzzy Expert System for Student Education Advisor (FES-SEA) and stays in university portal. This system implemented with ASP.NET, SQL-SERVER 2008.
\end{abstract}

Key words: Fuzzy Expert Systems (FES), knowledge based systems, Internet, web-based, Grade Point Average (GPA)

\section{INTRODUCTION}

The Decision Support Systems as a field of study in artificial intelligence are based in mimicking the behavior of human in problem solving and finding the pattern of solutions. In real world if no certain and straight-forward solution cannot be found for a specific problem, experts are asked for help. Experts, in their own way which often includes trial-and-error methods, solve the problem. Since, there is no specific solution for this kind of problem, defining the method of achieving the solution for a computer is difficult. Therefore, expert systems are used to reach that goal. In these systems, the program consists of asset of a set of rules. The knowledge in human's brain is also a set of if then rules. Goodarzi $(2009,2010)$ proposed the fuzzy application in Student Evaluating System, Portfolio Advisor System in which fuzzy concepts can help in converting many crisp inputs to specific linguistic variables and covering many entries with fuzzy rules and inference. In (Saini et al., 2002) a Web-Based Fuzzy Expert System is used to help inexperienced Indian farmers in pesticide of their farms.

The first version of this system was introduced in 1995 in a single-user form. In (Akhter et al., 2005) a Web-Based Fuzzy Expert System is proposed in the field of e-Commerce. In forums, usually somebody starts a discussion and expresses his/her opinions and approaches to a particular problem. Huang et al. (2008) proposes a model for creating a fuzzy-based expert forum that intelligently responds to questions asked by users. Finding the right broker at the right time is another issue that requires expertise. This may be the reason for which inexperienced investors loose in stock markets. In Merloti a Stock Expert System Model is proposed. The goal of this system is to make a good suggestion based on information about goods and market in order to reduce the loss and increase the benefit. Educational Consulting System tries to mimic the behavior of the staff addressing the educational consulting issues.

\section{LITERATURE REVIEW}

Each year in India, many farms are ruined due to pests attack because inadequate experience of the farmers. The loss was about 6.3 billion dollars in 2001 . Soybean Pest Expert System (SOYPEST) (Saini et al., 2002), a Fuzzy Expert System, asks fuzzy questions in order to generate a web-based response for the user. SOYPEST is created by using JESS and gradually became more accurate by receiving feedback from the users and the experts.

In e-Business, the buyers should be assisted when facing ambiguities during shopping and fuzzy expert systems can play an important role regarding that. In

Corresponding Author: Mahdi Hassani Goodarzi, Department of Software Engineering, Islamic Azad University, Malayer Branch, Malayer, Iran 
(Akhter et al., 2005) a Business to Customer (B2C) Model is proposed which seems to have a fundamental problem: the access level and competition are considered as fuzzy system rules. The major part of this research, concentrates on that and other issues in e-Commerce like demand for purchase, production of goods and the price are not included in the rule base. It is also considerable that provider sites can be included as a set of fuzzy rules in which various fuzzy sets (like the quality of goods, the number of customers on-line, the price available number of goods) are taken into account in decision making.

Interactive information interchange and creating forums on the web are important issues which attract many researchers. One of the best known tools for this purpose is VBulletin. There are reasons that support the possibility of receiving:

- Irrelevant answers

- No answers at all

- Different confusing answers from several other users

- Unclear answers

These reasons can be considered as the Achilles heel of such systems. In (Huang et al. 2008), linguistic expressions are categorized and then n-gram algorithm is used to edit and convert the sentences to a proper format. This system supports 15 languages and by default the questions are multiple choice questions. Although, the strong point of this system is its gradually improving knowledge base, the extended number and the expanded fields of topics, no considerable effort is done to find the best answer and the problem is solved through partial simulation of human's brain.

\section{DECISION SUPPORT SYSTEM (STUDENT CONSULTING EXPERT SYSTEM)}

Most of students face problems related to educational rules and regulations during their education. These rules and regulations are changing every now and then and therefore an expert is needed to memorize these rules in order to be able to help students in their issues.

The state of any student according to the rules and regulations may differ from that of other students. Student State (SS) is a member of a fuzzy set with a degree of membership equal to $\mu_{\text {ss }}$.

The first step: It determining and fuzzificating the inputs to the system by using fuzzy rules. Following are some of the fuzzy sets of the system in hand:
- Fuzzy set for GPA

- Fuzzy set for passed courses

- Fuzzy set for marks of selected courses

- Fuzzy set for the rank and grade of student in the entrance exam

- And so on

Fuzzifiction of the crisp variables of the model: Students can be categorized according to their GPA into groups like A-E. This categorization can be expressed through linguistic terms like Excellent, Good, Middle, Week, Very Week.

The second step: It determining the degree of membership of linguistic terms including 3 following phases.

Phase 1: For each term, the value nearest to the numeric equivalent of the linguistic term which has the maximum degree of membership is selected.

Here the highest value for the linguistic term Excellent is 20 and 0 has the highest value in Very Week fuzzy set.

Phase 2: For each term, the value (or values) which has (have) the membership degree of 0 is (are) determined.

Phase 3: Point with $\mu=1$ are connected to points with $\mu=0$ by lines to form a Gaussian (exponential) membership function. In cases in which there are more than one point with $\mu=1$, a Gaussian membership function is obtained. In the current model, membership functions can be Gaussian, Z-shaped and S-shaped (Fig. 1).

Rule extraction: After an interactive negotiation with experts, the obtained data are fuzzified. The previous section illustrates how GPA can be fuzzified. The following rules are the result of the negotiations:

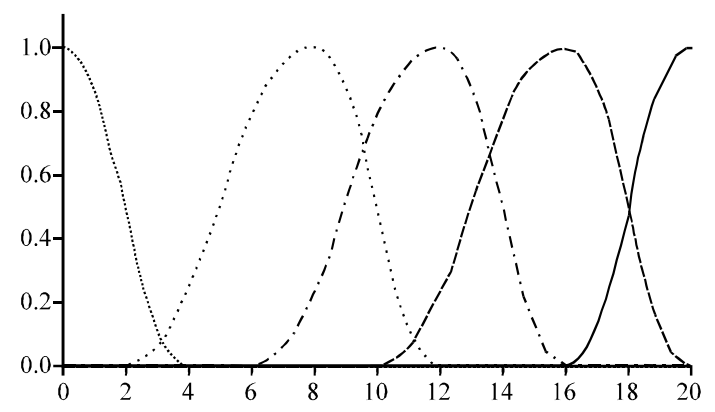

Fig. 1: GAP membership functions 


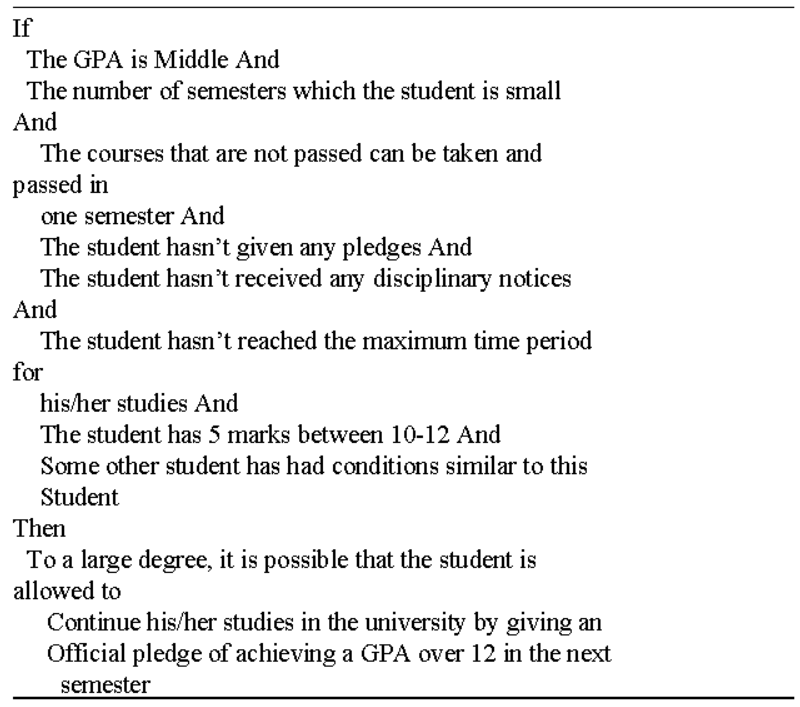

Data centralization: If the profiles of students are available in a centralized storage device even these negotiations are not necessary and the system can provide the answer by directly accessing a student's profile.

Putting the information on the web: Day by day development of the World Wide Web and applying multimedia tools along with the accessibility of web sites from any place in the world makes it feasible to design the user interface compatible with the web. Many expert systems in different fields of expertise are developed (EXSYS CORVID, XpertRuleKnowledge Builder) but few are applied.

Since, linguistic terms and fuzzy sets are used, the process for inference should be done on the client rater than the server so the server's busy time is reduced. This procedure can be done by using browser executable languages like JavaScript, Java, VB Script, XML, AJAX and Applet.

Considering the exclusion issue of a student: Before selecting the courses for the next semester, the students are checked and those who should be excluded are determined and prevented from registration for the next semester. The student's advisor should address his/her issue according to rules and regulations. Below are shown some questions and answers asked and answered by advisor and the student (respectively).

\section{A LOOK INSIDE THE SYSTEM}

My approach build on 5-tier layers and have a best performance on the web in Fig. 2 framework of system is shown:

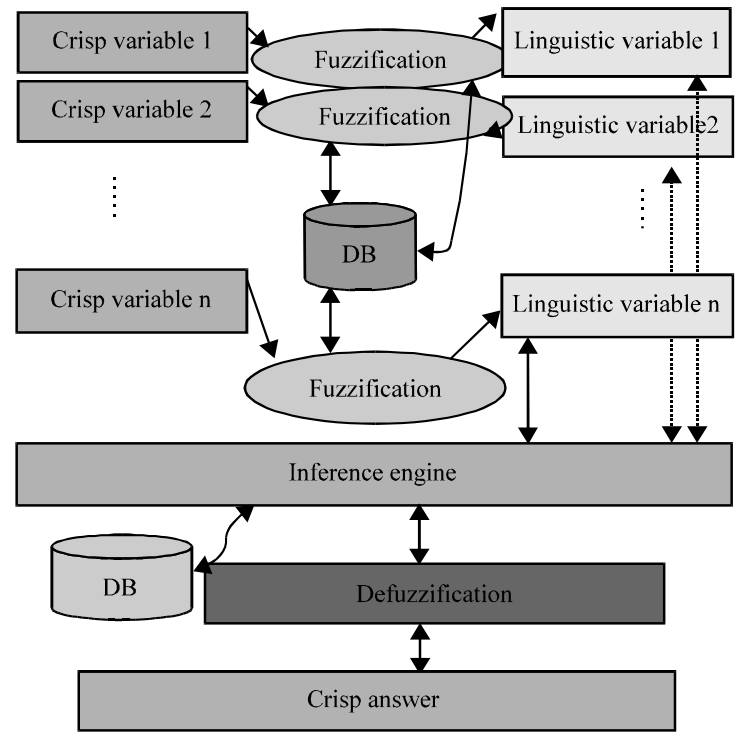

Fig. 2: Fuzzy System Framework

- First user enters data web forms

- Look fuzzy sets equal user input crisp values same GPA, eventual count, educational level and so on

- In crisp system variables is fuzzed and generates linguistic variables. This section achieve by one user defined function on the database by name Udf_Fuzzifier

- Linguistic variables send to inference engine and process with Mamdani Model (Siler and Buckley, 2005). This section accomplish by one stored procedure in database by name Stp_Inference

- Fuzzy answers defuzzyfies and output crisp values generate, this section accomplish by one user defined function in database, by name Udf_Defuzzifier

Finally advisor system evicts answer to user.

\section{IMPLEMENTATION ENVIRONMENT}

System solution has 3 layers:

- Web application layer include: boundary classes, web pages, functions and enumerations

- Business facade, business rules layer includes: control classes and methods, business classes and methods. List of classes are:

- FuzzyDecision.cs

- FuzzyLogic.cs

- FuzzyNumber.cs

- FuzzyPattern.cs 


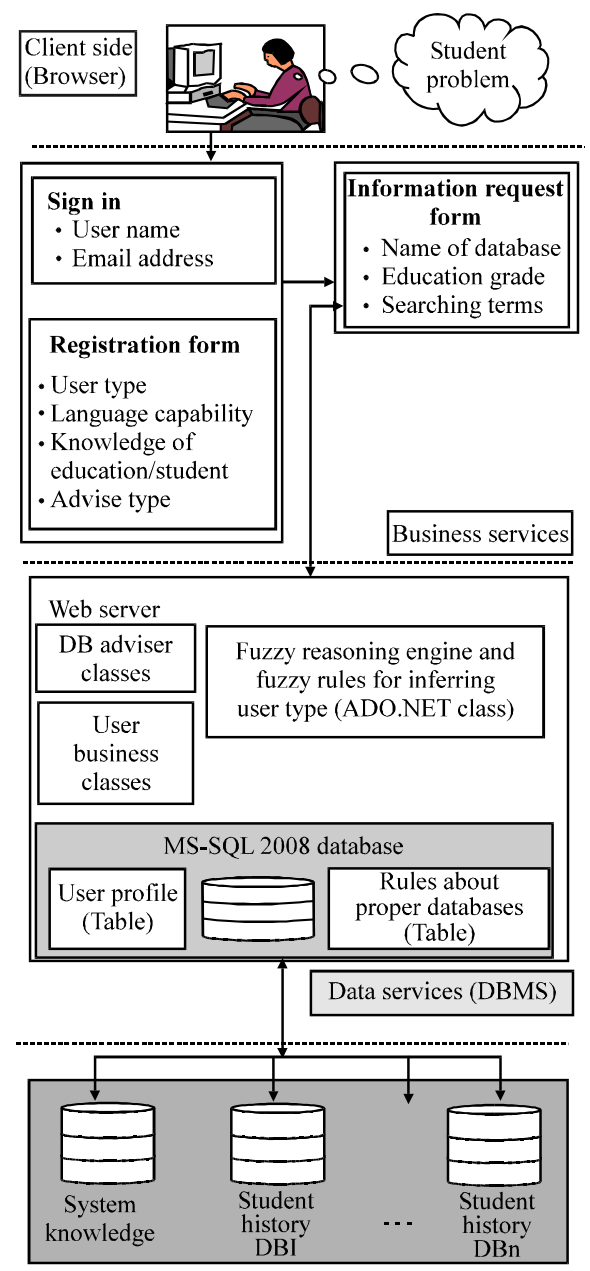

Fig. 3: Implemented System Model

- FuzzyRuleInference.cs

- FuzzySet.cs

- FuzzyWord.cs

The best section in my approach is data access layer that is one class by name: ClsDataAccess.cs and support ADO.NET frameworks and working connectionless completely. Structure of Fuzzy System architecture is shown in Fig. 2.

Structure of implemented system is shown in Fig. 3. First of all a student $\log$ in to the university portal and selects the educational advisor system link then selects his problem. System asks the questions that are related with this question. After fill the vacancies by student the FES inferences and answers to student.

\section{ADVANTAGES OF FUZZY EXPERT SYSTEMS}

The major advantage of these systems is that knowledge gradually turns into wisdom and can be used as a decision making tool in critical situations which replaces the conventional FAQ. Some other features are:

More accessibility: Many experiments can be done. Simply an expert system is a mass production of experiments.

Cost reduction: The cost of gaining experience by the user is decreased considerably.

Risk reduction: The Expert System can work in environments dangerous, harmful or unpleasant for human.

Eternality: These systems don't die.

Multiple experts: An expert system can be the result of knowledge elicitation of several experts.

More reliability: These systems don't get tired or sick, they don't go on a strike and they don't conspire against their managers. On the contrary, these are often done by experts.

Explanation capability: An expert system can explain the way in which the results are obtained. On the contrary, due to many reasons (fatigue, unwillingness, etc.) experts are not able to provide such explanations all the times.

Quick response: Expert systems respond quickly.

Responsibility in any condition: In critical conditions and/or emergencies an expert may be unable to make the right decision due to stress or other factors while an expert system's decision making is not affected by these events.

Experience base: An expert system can provide access to a massive amount of experience.

User training: An expert system can act like an intelligent tutor: problems are presented to the system and the way of reasoning can be obtained.

Ease of knowledge transmission: One of the most important advantages of expert systems is it is convenient to move the knowledge of the system somewhere else on the globe.

\section{ENVIRONMENT OF SOFTWARE}

The fuzzification and rule extraction page is shown in Fig. 4. The inferences defuzzification and make answer is shown in Fig. 5. 


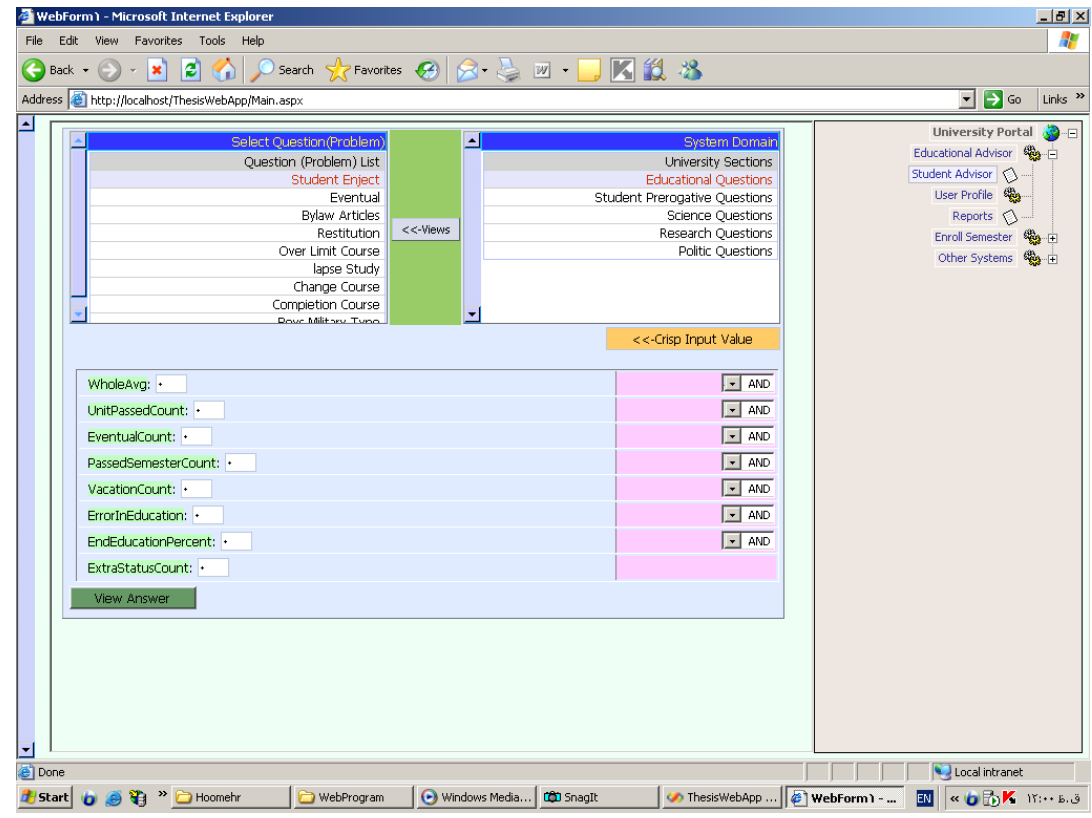

Fig. 4: Fuzzification and rule extraction page

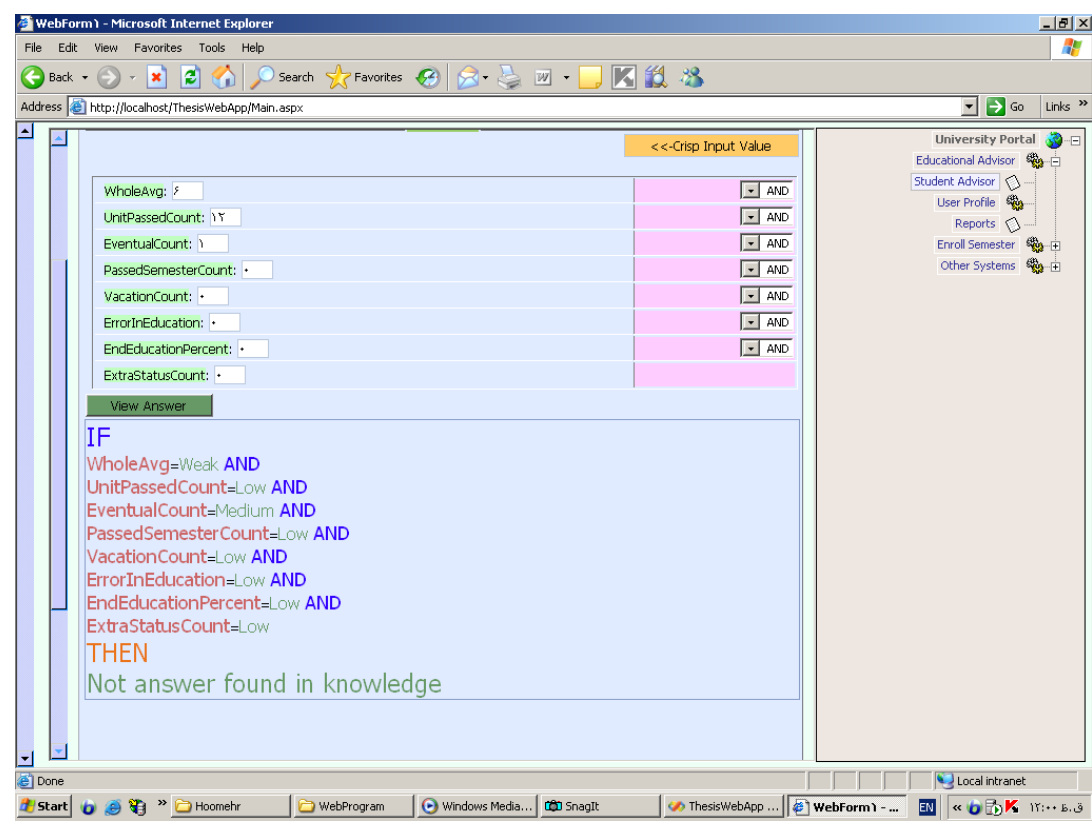

Fig. 5: Inference, defuzzification and make answer

\section{ONE REAL EXPERIMENT RESULT}

Student rejection request $\mathrm{Q}$ and $\mathrm{A}$. In this part of approach, researchers describe the one real $\mathrm{Q}$ and $\mathrm{A}$ between rejected student and his/her advisor teacher:

$\mathrm{Q}_{1}=$ Your total average?

$\mathrm{A}_{1}=12.18$
$\mathrm{Q}_{2}=$ How many units remain to pass?

$\mathrm{A}_{2}=8$

$\mathrm{Q}_{3}=$ How many pledges did you get before?

$\mathrm{A}_{3}=0$

$\mathrm{Q}_{4}=$ How many disciplinary did you get before?

$\mathrm{A}_{4}=1$

$\mathrm{Q}_{5}=$ How many semesters did you study?

$\mathrm{A}_{5}=9$ 
Table 1: Fuzzification experiment levels

\begin{tabular}{lccl}
\hline Question & Answer & Fuzzy variable/(fv) $\mu(\mathrm{x})$ & Linguistic variable \\
\hline 1 & 12.18 & 0.85 & Middle \\
2 & 8.00 & 0.86 & Small \\
3 & 0.00 & 1.00 & Small \\
4 & 1.00 & 0.25 & Middle \\
5 & 9.00 & 0.65 & High \\
6 & 8.00 & 0.76 & High \\
7 & 130.00 & 0.94 & High \\
\hline
\end{tabular}

$\mathrm{Q}_{6}=$ How many marks under number $10 ?$

$\mathrm{A}_{6}=8$

$\mathrm{Q}_{7}=$ How many units do you passed?

$\mathrm{A}_{7}=130$

The results of this $\mathrm{Q}$ and $\mathrm{A}$ are shown in Table 1 . Then, the rule-base system generates this rule.

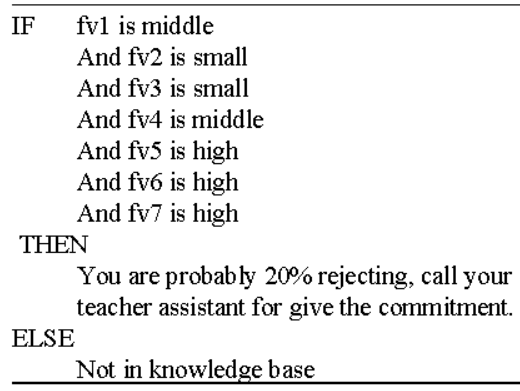

When the FES cannot find the solution for request entries, call the knowledge engineer for makes the new rules and insert into the knowledge DB.

\section{CONCLUSION}

In the beginning of this study a glance to definitions and introduction to fuzzy logic and fuzzy decision making was taken. Then, some implemented examples of such systems are presented and finally, a web-based student consulting expert system is proposed. In the end, the capability of the system in enhancing the consulting process is shown.

\section{ACKNOWLEDGEMENT}

This project supporting by the Islamic Azad University, Malayar Branch.

\section{REFERENCES}

Akhter, F., D. Hobbs and Z. Maamar, 2005. A fuzzy logicbased system for assessing the level of business-toconsumer (B2C) trust in electronic commerce. Exp. Syst. Applic., 28: 623-628.

Goodarzi, M.H., 2009. Evaluating students learning progress by using fuzzy expert systems. Proceedings of the 6th International Conference on Fuzzy Systems and Knowledge Discovery, August 14-15, 2009, Tianjin, China, pp: 561-565.

Goodarzi, M.H., 2010. A web-based Implementation of a portfolio advisor system based on fuzzy expert systems. Proceedings of the 6th International Conference of Information and Communication Technology and System, September 2010, Surabaya, Indonesia, pp: 15-22.

Huang, Y.M., J.N. Chen, Y.H. Kuo and Y.L. Jeng, 2008. An intelligent human-expert forum system based on fuzzy information retrieval technique. Exp. Syst. Applic., 34: 446-458.

Saini, H.S., R. Kamal and A.N. Sharma, 2002. Web based fuzzy expert system for integrated pest management in soybean. Int. J. Inf. Technol., 8: 55-74.

Siler, W. and J.J. Buckley, 2005. Fuzzy Expert Systems and Fuzzy Reasoning. John Wiley and Sons, USA. 